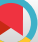

\title{
Protective Effect of Tea Grape Extract on Cisplatin-Induced Muscle Atrophy: A Morphological Study
}

\author{
Mehmet Sabri Balik ${ }^{1,{ }^{*}}$, Levent Tumkaya ${ }^{2}$, Tolga Mercantepe ${ }^{2}$, Adnan Yilmaz ${ }^{3}$, Gulsah Balik ${ }^{4}$, Atilla \\ Topcu $^{5}$ and Zihni Yazici ${ }^{6}$ \\ ${ }^{1}$ Department of Orthopedic and Traumatology, Recep Tayyip Erdogan University, Rize, Turkey \\ ${ }^{2}$ Department of Histology and Embryology, Medical Faculty, Recep Tayyip Erdogan University, Rize, Turkey \\ ${ }^{3}$ Department of Medical Biochemistry, Medical Faculty, Recep Tayyip Erdogan University, Rize, Turkey \\ ${ }^{4}$ Department of Obstetrics and Gynecology, Medical Faculty, Recep Tayyip Erdogan University, Rize, Turkey \\ ${ }^{5}$ Department of Medical Pharmacology, Medical Faculty, Recep Tayyip Erdogan University, Rize, Turkey \\ ${ }^{6}$ Department of Microbiology, Medical Faculty, Recep Tayyip Erdogan University, Rize, Turkey \\ "Corresponding author: Department of Orthopedic and Traumatology, Medical Faculty, Recep Tayyip Erdogan University, Rize, Turkey. Tel: +90-505823194, Email: \\ sabribalik@yahoo.com
}

Received 2018 January 15; Revised 2018 July 24; Accepted 2018 August 04.

\begin{abstract}
Background: Even though Cisplatin (Cis) is known to be organotoxic, it is used in neoplastic chemotherapy. In skeletal muscles, the toxic effect manifests as atrophy.

Objectives: The tea grape extract (TGE) is a sort of whortleberry that has various physiological effects including prevention of chemically induced cellular insults. Therefore, we examined if the TGE has a protective effect against the Cis induced skeletal muscle atrophy.

Methods: Female Sprague-Dawley rats were used in this animal experimental study. Rats were allocated into different study groups, each with eight members. The groups comprised control, solvent control, $200 \mathrm{mg}$ TGE, Cis, Cis + $100 \mathrm{mg}$ TGE, and Cis + $200 \mathrm{mg}$ TGE. Results: The mean fiber area of the skeletal muscle (MFASM) decreased significantly in the Cis group in comparison to the control group $(\mathrm{P}=0.01)$. MFASM showed similarities between the Cis + TGE 200 and control groups $(P>0.05, P=0.418)$. Similarities were also observed for MFASM between the Cis $+100 \mathrm{mg}$ TGE and Cis $+200 \mathrm{mg}$ TGE groups $(\mathrm{P}>0.05, \mathrm{P}=0.891)$. The mean serum calcium level in the Cis group (10.26 \pm 0.29$)$ was significantly higher in TGE $100(9.13 \pm 0.11)$ and TGE 200 groups $(9.21 \pm 0.13)$.

Conclusions: It is concluded that the tea grape extract has a protective effect on Cis-induced toxicity of the skeletal muscles.
\end{abstract}

Keywords: Atrophy, Chemotherapy, Cisplatin, Myofibroblast, Muscle, Plant Extracts, Skeletal, Tea Grape Extract

\section{Background}

Cisplatin (Cis) is used as an antineoplastic drug in chemotherapy. It has toxic effects in numerous organs. This toxic effect limits the therapeutic efficacy. Even though the mechanism of organ toxicity is not clear, it has been reported that the oxidative damage (1) might be related to inflammation and cellular apoptosis (2). It has been demonstrated that Cis, acting through impairment of the Akt pathway, behaved as a potent trigger for atrophy via the ubiquitin-proteasome and autophagy lysosome systems $(3,4)$.

Platinum-containing drugs, such as Cisplatin, are chemotherapeutic agents that are known to induce weight and muscle mass loss. Cisplatin is part of standard care in the treatment of various cancers, including lung, head, neck, ovarian, testicular, and bladder cancers; preventing
DNA replication by diverse mechanisms (5). The loss of muscle mass and function during treatment with Cis is a result of interference with multiple enzymatic pathways including protein synthesis (6).

One of the most common side effects of Cis use is muscle fatigue, which may result from muscular damage, the exact mechanism of which remains undetermined $(7,8)$. In addition, during the treatment with Cis, the disease itself and inactivity of the patient together lead to catabolic events in the skeleton, causing severe atrophy and increasing morbidity (9-13). These adverse effects limit the clinical use of Cisplatin and similar drugs (14). New agents or supporting products are required to counter these adverse effects (15).

Skeletal muscles (SM) are tissues consisting of myofibril proteins. SM renovates the protein bundles and exhausted organelles such as mitochondria and sar- 
coplasmic reticulum in order to maintain an efficient metabolism (16). Starvation, aging, anorexia, or several toxic or inflammatory disorders have been shown to activate the excessive catabolism in muscles that exerts progressive atrophy $(3,4,16,17)$. Besides, $\mathrm{Ca}^{++}$plays a vital role in the conduction of skeletal muscle function. Excessive intracellular free $\mathrm{Ca}^{++}$disturbs the muscular working power, causing deterioration of the normal function. This is mainly due to aging, inactivity, and loosely related muscle toxicity (18-20). The impairment of $\mathrm{Ca}^{++}$ homeostasis, as a result of myotoxicity of the drug, may cause some pathophysiological events to occur; however, the precise cause remains unidentified (21).

Whortleberry, Vaccinium myrtillus, is a species of the Ericaceous family, which is the source of TGE (22). TGE is a promising medication due to its high anthocyanin like red currant $(22,23)$. Even though whortleberry extract has antineoplastic, anti-inflammatory, and neuroprotective effects in rats, its effect on muscles is unknown (24). The potent antioxidant property of whortleberry has been shown to correlate with protection against drug-induced toxicity in cardiomyocytes (25).

\section{Objectives}

In cancer prevention and treatment, alternative care with supplements is on the increase. Although the effects of food supplements in cancer treatment have not yet been fully elucidated, previous studies have shown that antiinflammatory and antioxidant effects of these agents contribute to enhancing the well-being of patients by reducing the potential adverse effects of drugs used in clinical therapy (26-28).

Therefore, in this study, we aimed to investigate the potential protective effects of the tea grape extract on Cisplatin-induced muscle atrophy in rats.

\section{Methods}

\subsection{Animal Study}

In this animal experimental study, 48 adult SpraqueDawley female rats (about three months of age and weighing $250 \pm 100 \mathrm{~g}$ ) were reared in the Recep Tayyip Erdogan University's Animal Care and Research Unit facility in Rize, Turkey in 2016. The animals were allocated into 6 groups of 8 at random (Table 1). The rats were housed in clean polypropylene cages with eight animals per cage (29). During the experimental period, all rats were provided with pellets containing 21\% crude protein (Purina; Nestle Purina PetCare Company, St Louis, MO) and drinking water.
The animals were cared for according to the criteria outlined in the guide for the care and use of laboratory animals prepared by the National Academy of Sciences and published by the National Institutes of Health. The animal experimental study was approved by the Recep Tayyip Erdogan University Institutional Animal Ethical Committee (Approval number: 2016/32).

\begin{tabular}{ll}
\hline Table 1. Experimental Groups $\left(\mathrm{n}=8 /\right.$ group $^{\mathrm{a}}$ \\
\hline Groups & Treatment \\
\hline $\mathbf{1}$ & Not applicable \\
$\mathbf{2}$ & Sham (distilled water + ethanol) \\
$\mathbf{3}$ & TGE $200 \mathrm{mg}$ \\
$\mathbf{4}$ & Cis \\
$\mathbf{5}$ & Cis + TGE $100 \mathrm{mg}$ \\
$\mathbf{6}$ & Cis + TGE $200 \mathrm{mg}$ \\
\hline
\end{tabular}

${ }^{a}$ Group 1; This Group Was Not Injected with Medication. Group 2; Sham Control Group Containing Distilled Water and Ethanol. Group 3; TGE Control Group Received Only Intraperitoneal Injection of $200 \mathrm{mg} / \mathrm{kg}$, Distilled Water and Ethanol. Group 4; Single Dose Cisplatin Application Group Was Given Only Intraperitoneal $16 \mathrm{mg} / \mathrm{kg}$ Single Dose Cis. Group 5; $16 \mathrm{mg} / \mathrm{kg}$ Cis and $100 \mathrm{mg} / \mathrm{kg}$ Tea Grape Extract(TGE) Group Were Determined. Group 6;16 mg/kg Cis and 200 $\mathrm{mg} / \mathrm{kg}$ TGE Group.

\subsection{Drug Preparation and Experimental Protocols}

The TGE herbal liquids (Health Aid, UK), containing 330 $\mathrm{mg}$ of TGE per $\mathrm{mL}$ of ethanol and distilled water as a nutritional supplement, was diluted in ethanol and distilled water to $50 \mathrm{mg} / \mathrm{mL}$.

\subsection{Intervention Methods in the Study}

All drug administrations were in the form of intraperitoneal (IP) injections. Cis (16 mg/kg) (Cis DBL $100 \mathrm{mg} / 100$ $\mathrm{mL}$ vial, Orna Ilac, Istanbul) was administered, where indicated, as a single injection on the 5th day. Group 1 (control group) received no medication. Group 2 (solvent control/sham group) was given TGE solvent only, which is distilled water and ethanol for eight days. Group 3 (TGE 200 $\mathrm{mg}$ ) received $200 \mathrm{mg} / \mathrm{kg}$ TGE per day for eight days

Group 4 (Cis group) received Cis only. Group 5 (Cis + $100 \mathrm{mg}$ TGE group) was administered Cis and $100 \mathrm{mg} / \mathrm{kg}$ TGE per day for eight days. Group 6 (Cis $+200 \mathrm{mg}$ TGE group) was administered Cis and $200 \mathrm{mg} / \mathrm{kg}$ TGE/day for eight days. All animals were euthanized under anesthesia at the end of the experiment. All rats were anesthetized with $50 \mathrm{mg} / \mathrm{kg}$ Ketamine hydrochloride (Ketalar@, Eczacibasi Parke-Davis, Istanbul, Turkey) and 10 $\mathrm{mg} / \mathrm{kg}$ Xylazine HCl IP(Alfazyne $®$, Alfasan International BV Woerden, Holland). All chemicals were from Sigma Chemical Co. and Merck, (Germany) unless otherwise stated. 


\subsection{Histological Analysis}

The Quadriceps muscle was removed from all animals. The length of the muscle was measured and the mid-point was identified, where SM tissue samples were taken. The SM tissues were fixed in 10\% neutral formaldehyde. After 72 hours, the tissue blocks were subjected to dehydration in an increased alcohol series, clearing through a xylene series, immersion in liquid paraffin, and embedding in paraffin blocks. From the paraffin blocks of each rat, four $5-\mu \mathrm{m}$ serial sections with intervals of $50 \mu \mathrm{M}$ were taken using a microtome (Leica RM2125RT, Nussloch, Germany).

The sections were then deparaffinized, rehydrated, and stained with Hematoxylin and Eosin (H\&E) in accordance with standard protocols followed by photography with a camera attached to a light microscope (Nikon Eclipse E600, Japan). The same illumination settings were used for photography in order to permit comparative evaluation by a histologist.

\subsection{Biochemical Processes}

Blood samples $(3.0 \mathrm{~mL})$ were taken from the left ventricle of the animals for the measurement of electrolytes such as Ca using a standard auto-analyzer (Architect c16000 Autoanalyzer, Abbott Diagnostics, Waltham, Massachusetts, USA). Normal Ca level 9.1 - $15.1 \mathrm{mg} / \mathrm{dL}$ in Spraque-Dawley rats. The Ca levels in the control group were as reported elsewhere (29).

\subsection{Quantitative Analysis}

The SM areas were calculated using the Olympus DP2BSW system (Ver.2.1 to Ver.2.2, Build 6212, Tokyo, Japan). This system consists of a camera attached to a light microscope and a computer with the relevant software. The sectional boundaries of the H\&E stained sections were determined and the separate frames were identified by a histologist. The results were expressed as $\mu \mathrm{M}^{2}$.

\subsection{Statistical Analysis}

Biochemical and quantitative data analysis was performed using IBM SPSS Statistics for Windows, version 21.0 (IBM Corp., Armonk, N.Y., USA). Descriptive data were presented as means \pm standard deviation. Since the data showed a normal distribution after Shapiro-Wilk and Levene's test, ANOVA was used in order to detect any relationship between the means of serum Ca, mean area of the skeletal muscle in the experimental, and control groups. A P value of $<0.05$ was considered statistically significant. Duncan's test was used as a post-hoc test in order to identify differences between groups.

\section{Results}

In the SM tissues of the control, sham, and TGE $200 \mathrm{mg}$ groups, the structure of the myofibrils was normal (Figure $1 \mathrm{~A}$ ). A total of $200 \mathrm{mg}$ TGE did not cause any pathological changes (Figures $1 \mathrm{~B}$ and $1 \mathrm{C}$ ). Cis induces progressive fibrosis and atrophy, muscular atrophy, and intense substitution of the parenchyma by fibrous tissue in the SM. In the Cis group, fibrosis was indicated by the concomitant collagen deposition. The atrophic myofibril area and the contractile proteins that they contain decreased (Figure 1D). The integrity of the SM tissue was normal in the Cis $+100 \mathrm{mg}$ TGE group. The intensity of atrophic myofibers decreased more than those in the Cis group (Figure $1 \mathrm{E}$ ). The general structure of the SM tissue of the Cis + $200 \mathrm{mg}$ TGE group was normal. The myofibers and their contractile proteins had normal structures (Figure 1F). Assessments of fiber area $\left(\mu \mathrm{M}^{2}\right)$ of SM tissues of all groups are presented in Table 2. The mean of the fiber area of the SM decreased significantly in the Cis group when compared to control group $(\mathrm{P}=0.01)$. The mean areas of fibers were similar in the sham and TGE $200 \mathrm{mg}$ groups ( $\mathrm{P}>0.05)$, which were respectively, $\mathrm{P}=0.730$ and $\mathrm{P}=0.831$. Mean fiber areas of rats showed similarities in the Cis + TGE $200 \mathrm{mg}$ and control groups $(\mathrm{P}>0.05, \mathrm{P}=0.418)$. Similarities were also observed in the mean fiber areas in the Cis + TGE $100 \mathrm{mg}$ and Cis + TGE 200 mg groups $(\mathrm{P}>0.05, \mathrm{P}=0.891)$. Fiber area $\left(\mu \mathrm{M}^{2}\right)$ box-plot graphs are presented in Figure 2 .

\begin{tabular}{|c|c|}
\hline Groups & Fiber Area, mean $\pm S D$ \\
\hline Control & $1559,80 \pm 196.71^{\mathrm{b}}$ \\
\hline Sham & $1460.01 \pm 153.15^{\mathrm{b}}$ \\
\hline TGE200 mg & $1473.63 \pm 61.33^{c}$ \\
\hline Cis & $1181.18 \pm 102,97$ \\
\hline Cis + TGE100 mg & $1347.03 \pm 73.03^{\mathrm{b}, \mathrm{c}}$ \\
\hline Cis + TGE200 mg & $1423.36 \pm 97,76^{\mathrm{b}, \mathrm{c}, \mathrm{d}}$ \\
\hline \multicolumn{2}{|c|}{$\begin{array}{l}\text { Abbreviations: Cis, Cisplatin; TGE, Tea Grape extract. } \\
{ }^{\mathrm{a}} \text { The Mean of the Fiber Area of Cis Group When Compared to Control Group (P } \\
=0.01) \text {. Sham and TGE } 200 \mathrm{mg} \text { Groups }(\mathrm{P}=0.730) \text {. Cis + TGE } 200 \mathrm{mg} \text { and Control } \\
\text { Groups }(\mathrm{P}=0,418) \text {. Cis + TGE } 100 \mathrm{mg} \text { and Cis + TGE } 200 \mathrm{mg} \text { Groups }(\mathrm{P}=0.891) . \\
\mathrm{b} P<0.05 \text { (vs. Cis). } \\
{ }^{\mathrm{c}} \mathrm{P}>0.05 \text { (vs. control). } \\
\mathrm{d} P>0.05 \text { (vs. Cis + TGE100 mg). }\end{array}$} \\
\hline
\end{tabular}

The mean serum Ca level of all rats was $9.57 \pm 0.11$. The mean serum Ca level significantly differed between the groups ( $\mathrm{P}=0.001)$. The lowest mean level of serum $\mathrm{Ca}$ was found in the TGE-100 mg group, while the highest was in the Cis group. After Duncan's test, it was determined that the significant differences be between the Cis and TGE groups. The mean serum $\mathrm{Ca}$ in the Cis group (10.26 \pm 0.29$)$ 

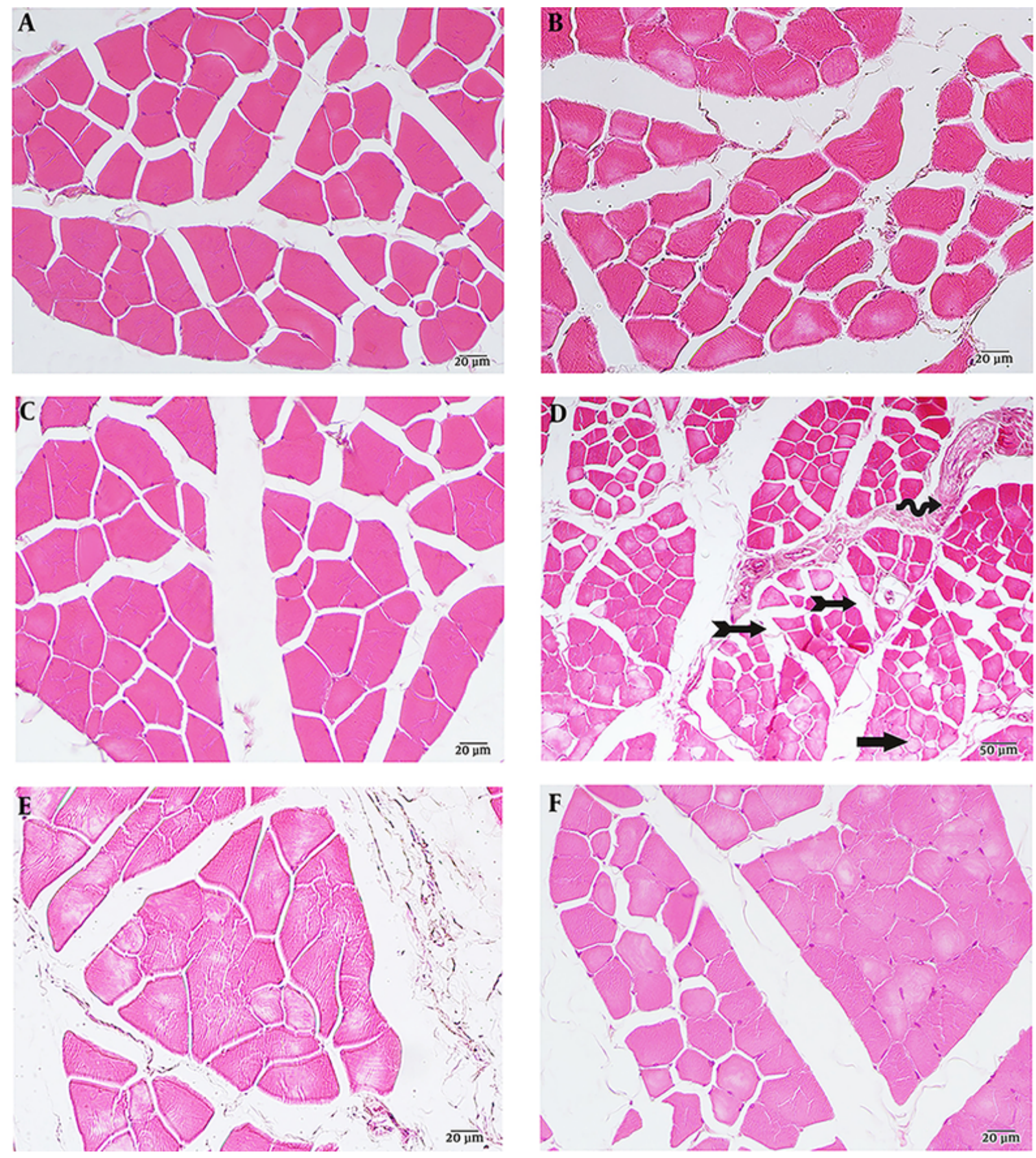

Figure 1. SM histology (H\&E staining). (A) Control group with normal SM structure $\times 400$. (B) Sham group $\times 400$, (C) TGE 200 mg group, (D) Cis group displaying muscula atrophy with an intense substitution of the parenchyma by fibrous tissue (spiral arrow) as a result of collagen deposition $\times 200,(\mathrm{E})$ Cis + TGE 100 mg group $\times 400$, (F) Cis + TGE $200 \mathrm{mg}$ group. Tailed arrows indicate a decrease in the muscle fiber. The arrow shows muscle fibers with smaller diameters due to decreased contractile proteins $\times 400$ Abbreviations: Cis, Cisplatin; TGE, Tea Grape extract.

was significantly higher than the TGE-100 $\mathrm{mg}(9.13 \pm 0.11)$ and the TGE-200 mg groups ( $9.21 \pm 0.13$ ) (Table 3$)$. The error bars indicating the $95 \%$ confidence interval of serum
Ca levels are presented in Figure 3.

Iran Red Crescent Med J. 2018; 20(9):e66319. 


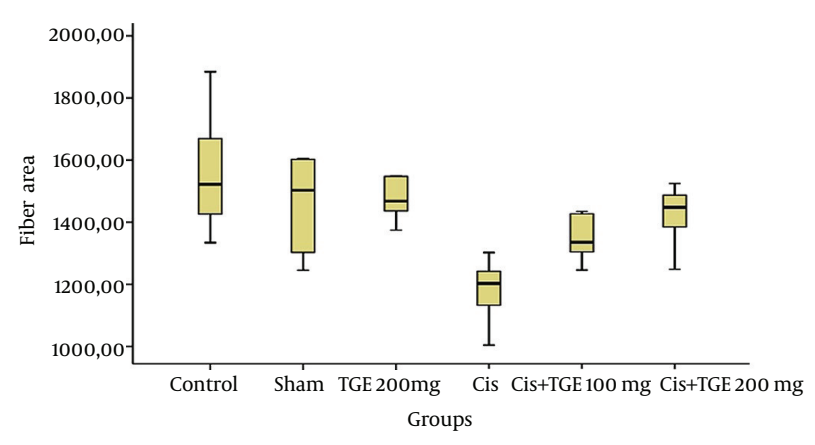

Figure 2. Box-plot of the fiber area $\left(\mu \mathrm{m}^{2}\right)$ of the groups. The mean of the fiber area of the SM decreased significantly in the Cis group when compared to control group $(\mathrm{P}=0.01)$. Sham and TGE $200 \mathrm{mg}$ groups $(\mathrm{P}=0.730, \mathrm{P}=0.831)$. Cis + TGE $200 \mathrm{mg}$ and control groups $(\mathrm{P}>0.05, \mathrm{P}=0,418)$. Cis + TGE $100 \mathrm{mg}$ and Cis + TGE $200 \mathrm{mg}$ groups $(\mathrm{P}>0.05, \mathrm{P}=0.891)$. Abbreviations: $\mathrm{Cis}$, Cisplatin; TGE, Tea Grape extract.

\begin{tabular}{ll}
\hline Table 3. Serum Ca Concentrations in $\mathrm{mg} / \mathrm{dL}^{\mathrm{a}, \mathrm{b}}$ & \\
\hline & Mean \pm SD \\
\hline TGE 100mg + Cis & $9.13 \pm 0.30$ \\
TGE 200mg + Cis & $9.21 \pm 0.35$ \\
Cis & $10.26 \pm 0.71$ \\
Control & $9.75 \pm 0.24$ \\
\hline
\end{tabular}

Abbreviations: Cis, Cisplatin; TGE, Tea Grape extract.

${ }^{\text {a }}$ The Mean Serum Ca level Was Significantly Different Between the Groups ( $\mathrm{P}<$ $0.05)$.

${ }^{\mathrm{b}} \mathrm{P}=0.001$, ANOVA test.

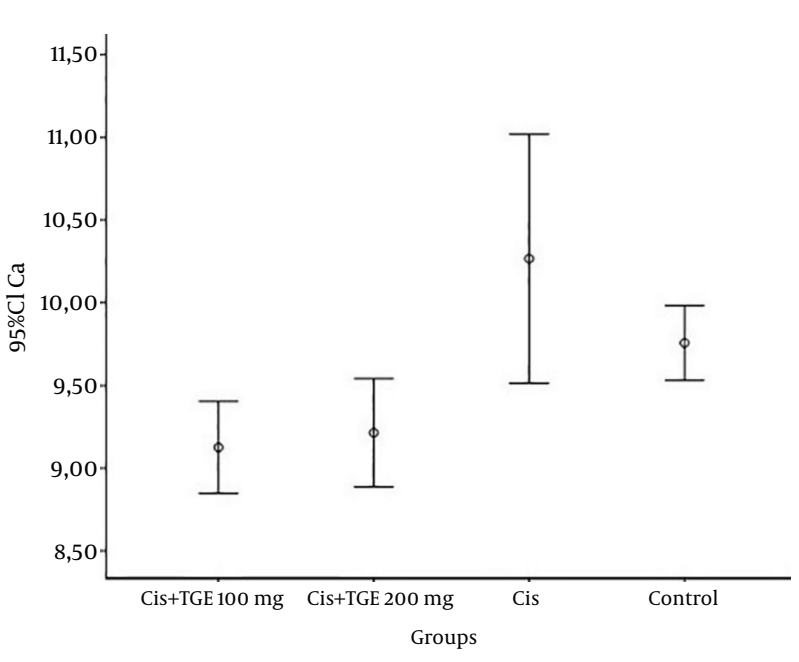

Figure 3. Serum calcium levels were shown as error bars in all groups. The mean serum Ca level significantly differed between the groups $(\mathrm{P}=0.001)$. Cis group $(10.26$ $\pm 0.29)$, TGE-100 $\mathrm{mg}(9.13 \pm 0.11)$ and TGE-200 $\mathrm{mg}$ groups $(9.21 \pm 0.13)$. Abbreviations: Cis, Cisplatin; TGE, Tea Grape extract.

\section{Discussion}

SM is one of the tissues having the highest volume within a human body. For this reason, SM is frequently af- fected by toxic effect, degenerative diseases, and mechanic injuries. Muscle atrophy might occur as a result of toxicity induced by Cis, which is one of the anticancer medications. Therefore, the prevention of Cis-induced muscle atrophy is critical $(6,10,12,17,21,30)$. Hojman and colleagues have shown that a dynamic lifestyle, as a result of Cis-induced muscle loss, can reverse this negative effect, and that muscle loss can be prevented in Cis treated mice (31). After a muscular injury, there is a potential for regeneration and remodeling, albeit incompletely. The change in shape and function, following physical exercise and re-innervation, are evidence of this (32).

Cis toxicity causes an increase in pro-inflammatory cytokines through the creation of reactive oxygen species and oxidative stress. These cytokines induce apoptosis and cell damage. Reactive oxygen species damage the cell membrane via neutrophil activation and lipid peroxidation $(7,33)$. As a result of this process, atrophy occurs in muscle tissue $(3,4,14,16,32)$.

In our study, an increase was observed in atrophic myofibrils. The mean fiber area measurements showed a statistically significantly higher increase in the Cis + TGE 100 $\mathrm{mg}$ and $200 \mathrm{mg}$ groups when compared to Cis only group $(\mathrm{P}<0.05)$. In addition, the Cis + TGE $200 \mathrm{mg}$ group had a significantly higher mean fiber area than the Cis + TGE $100 \mathrm{mg}$ group $(\mathrm{P}>0.05)$. This increase indicates the dosedependent protective effect of the extract on SK against Cis toxicity.

Among the berries, the TGE has the highest level of antioxidant effect (34). Its biological activity is related to polyphenols like flavonoids and anthocyanin $(24,35)$. This polyphenolic content creates the blue-black color of the berry and its antioxidant effect. TGE is effective for the treatment of inflammatory conditions and oxidative stress as has been shown for ocular and cardiovascular disorders $(32,36,37)$. This study has confirmed the previous findings in the context of Cis induced SM atrophy. Calcium ion plays a multitude of roles in the biological processes such as mitotic division. Calcium regulation disorders might result in cell death. The increase in calcium concentration can be better controlled via apoptosis $(33,38,39)$. For this reason, the regulation of calcium concentration is critical. Bhat and colleagues found that Ca- induced muscle loss can be partially replaced (40). In another study, Wagatsuma et al., reported that immobilization induced musculoskeletal atrophy can be partially cured by preventing calcium losses (41). In our study, there was an increase in Ca levels in the study groups when compared to the control group; however, the difference was statistically insignificant ( $\mathrm{P}>$ 0.05). It is thought that high serum Ca levels occur due to Cis-induced SM toxicity. In this study, the Ca levels in Cis + TGE group decreased significantly $(\mathrm{P}<0.05)$. Thus, TGE re- 
duces the Ca concentration that is elevated as a result of $\mathrm{Cis}$ toxicity $(\mathrm{P}<0.05)$.

When the toxic effect of Cis on SM was histologically examined, the characteristics of SM in Cis + $100 \mathrm{mg}$ TGE and Cis + $200 \mathrm{mg}$ TGE groups were similar to those of the control groups, confirming protection of the tissue against $\mathrm{Cis}$ toxicity.

\subsection{Limitations of This Study}

This was a quantitative study in which SM loss induced by Cis use was going to be counteracted by new agents. Therefore, indetermination of oxidant and anti-oxidant molecular levels is a major limitation.

In conclusion, the tea grape extract prevents Cisinduced toxicity of the skeletal muscle in a dosedependent manner. Therefore, the use of nutritional supplements for the reduction of muscle atrophy caused by chemotherapy-induced toxicity could be recommended.

\section{References}

1. Bentli R, Parlakpinar H, Polat A, Samdanci E, Sarihan ME, Sagir M. Molsidomine prevents cisplatin-induced hepatotoxicity. Arch Med Res. 2013;44(7):521-8. doi: 10.1016/j.arcmed.2013.09.013. [PubMed: 24120390].

2. Ademiluyi AO, Oboh G, Agbebi OJ, Akinyemi AJ. Anthocyanin - rich red dye of hibiscus sabdariffa calyx modulates cisplatin-induced nephrotoxicity and oxidative stress in rats. Int J Biomed Sci. 2013;9(4):243-8. [PubMed: 24711761]. [PubMed Central: PMC3884795].

3. Stacchiotti A, Rovetta F, Ferroni M, Corsetti G, Lavazza A, Sberveglieri G, et al. Taurine rescues cisplatin-induced muscle atrophy in vitro: A morphological study. Oxid Med Cell Longev. 2014;2014:840951. doi: 10.1155/2014/840951. [PubMed: 24955211]. [PubMed Central: PMC4053152].

4. Vinciguerra M, Musaro A, Rosenthal N. Regulation of muscle atrophy in aging and disease. Adv Exp Med Biol. 2010;694:211-33. [PubMed: 20886766].

5. Hatakeyama S, Summermatter S, Jourdain M, Melly S, Minetti GC, Lach-Trifilieff E. ActRII blockade protects mice from cancer cachexia and prolongs survival in the presence of anti-cancer treatments. Skelet Muscle. 2016;6:26. doi: 10.1186/s13395-016-0098-2. [PubMed: 27462398]. [PubMed Central: PMC4960708].

6. Garcia JM, Scherer T, Chen JA, Guillory B, Nassif A, Papusha V, et al. Inhibition of cisplatin-induced lipid catabolism and weight loss by ghrelin in male mice. Endocrinology. 2013;154(9):3118-29. doi: 10.1210/en.2013-1179. [PubMed: 23832960]. [PubMed Central: PMC3749475].

7. Damrauer JS, Stadler ME, Acharyya S, Baldwin AS, Couch ME, Guttridge DC. Chemotherapy-induced muscle wasting: Association with NF-kappaB and cancer cachexia. Eur J Transl Myol. 2018;28(2):7590. doi: 10.4081/ejtm.2018.7590. [PubMed: 29991992]. [PubMed Central: PMC6036305].

8. Michailidis Y, Karagounis LG, Terzis G, Jamurtas AZ, Spengos K, Tsoukas D, et al. Thiol-based antioxidant supplementation alters human skeletal muscle signaling and attenuates its inflammatory response and recovery after intense eccentric exercise. Am J Clin Nutr. 2013;98(1):233-45. doi: 10.3945/ajcn.112.049163. [PubMed: 23719546].
9. Wang $\mathrm{XH}$, Mitch WE. Mechanisms of muscle wasting in chronic kidney disease. Nat Rev Nephrol. 2014;10(9):504-16. doi: 10.1038/nrneph.2014.112. [PubMed: 24981816]. [PubMed Central: PMC4269363].

10. Sakai H, Kimura M, Isa Y, Yabe S, Maruyama A, Tsuruno Y, et al. Effect of acute treadmill exercise on cisplatin-induced muscle atrophy in the mouse. Pflugers Arch. 2017;469(11):1495-505. doi: 10.1007/s00424-0172045-4. [PubMed: 28762162].

11. Hirayama Y, Nakanishi R, Maeshige N, Fujino H. Preventive effects of nucleoprotein supplementation combined with intermittent loading on capillary regression induced by hindlimb unloading in rat soleus muscle. Physiol Rep. 2017;5(4). doi: 10.14814/phy2.13134. [PubMed: 28242821]. [PubMed Central: PMC5328772].

12. Coletti D. Chemotherapy-induced muscle wasting: An update. Eur J Transl Myol. 2018;28(2):7587. doi: 10.4081/ejtm.2018.7587. [PubMed: 29991991]. [PubMed Central: PMC6036312].

13. Versteeg KS, Blauwhoff-Buskermolen S, Buffart LM, de van der Schueren MAE, Langius JAE, Verheul HMW, et al. Higher muscle strength is associated with prolonged survival in older patients with advanced cancer. Oncologist. 2018;23(5):580-5. doi: 10.1634/theoncologist.2017-0193. [PubMed: 29222198]. [PubMed Central: PMC5947445]

14. Fanzani A, Zanola A, Rovetta F, Rossi S, Aleo MF. Cisplatin triggers atrophy of skeletal C2C12 myotubes via impairment of Akt sig nalling pathway and subsequent increment activity of proteasome and autophagy systems. Toxicol Appl Pharmacol.2011;250(3):312-21. doi: 10.1016/j.taap.2010.11.003. [PubMed: 21074548].

15. Chen MC, Hsu WL, Hwang PA, Chen YL, Chou TC. Combined administration of fucoidan ameliorates tumor and chemotherapyinduced skeletal muscle atrophy in bladder cancer-bearing mice. Oncotarget. 2016;7(32):51608-18. doi:10.18632/oncotarget.9958. [PubMed: 27323407]. [PubMed Central: PMC5239500].

16. Waseem M, Parvez S. Mitochondrial dysfunction mediated cisplatin induced toxicity: Modulatory role of curcumin. Food Chem Toxicol. 2013;53:334-42. doi: 10.1016/j.fct.2012.11.055. [PubMed: 23246825].

17. Muscaritoli M, Lucia S, Molfino A, Cederholm T, Rossi Fanelli F. Muscle atrophy in aging and chronic diseases: Is it sarcopenia or cachexia? Intern Emerg Med. 2013;8(7):553-60. doi: 10.1007/s11739-0120807-8. [PubMed: 22773188].

18. Gumpper K, Sermersheim M, Zhu MX, Lin PH. Skeletal muscle lysosomal function via cathepsin activity measurement. Methods Mol Biol. 2019;1854:35-43. doi: 10.1007/7651_2017_64. [PubMed: 28842895]. [PubMed Central: PMC5828979].

19. Sorimachi H, Ono Y. Regulation and physiological roles of the calpain system in muscular disorders. Cardiovasc Res. 2012;96(1):1122. doi: 10.1093/cvr/cvs157. [PubMed: 22542715]. [PubMed Central: PMC3444232].

20. Fraysse B, Desaphy JF, Rolland JF, Pierno S, Liantonio A, Giannuzzi $\mathrm{V}$, et al. Fiber type-related changes in rat skeletal muscle calcium homeostasis during aging and restoration by growth hormone. Neurobiol Dis. 2006;21(2):372-80. doi: 10.1016/j.nbd.2005.07.012. [PubMed: 16153853].

21. Isaac ST, Tan TC, Polly P. Endoplasmic reticulum stress, calcium dysregulation and altered protein translation: Intersection of processes that contribute to cancer cachexia induced skeletal muscle wasting. Curr Drug Targets. 2016;17(10):1140-6. [PubMed: 25882219].

22. Burdulis D, Sarkinas A, Jasutiene I, Stackevicene E, Nikolajevas L, Janulis V. Comparative study of anthocyanin composition, antimicrobial and antioxidant activity in bilberry (Vaccinium myrtillus L.) and blueberry (Vaccinium corymbosum L.) fruits. Acta Pol Pharm. 2009;66(4):399-408. [PubMed: 19702172].

23. Ogawa K, Sakakibara H, Iwata R, Ishii T, Sato T, Goda T, et al Anthocyanin composition and antioxidant activity of the Crowberry (Empetrum nigrum) and other berries. J Agric Food Chem. 2008;56(12):4457-62. doi: 10.1021/jf800406v. [PubMed: 18522397]. 
24. Wu X, Beecher GR, Holden JM, Haytowitz DB, Gebhardt SE, Prior RL. Concentrations of anthocyanins in common foods in the United States and estimation of normal consumption. J Agric Food Chem. 2006;54(11):4069-75. doi:10.1021/jf060300l. [PubMed: 16719536].

25. Ashour OM, Elberry AA, Alahdal A, Al Mohamadi AM, Nagy AA, AbdelNaim $A B$, et al. Protective effect of bilberry (Vaccinium myrtillus) against doxorubicin-induced oxidative cardiotoxicity in rats. Med Sci Monit. 2011;17(4):BR110-5. [PubMed: 21455099]. [PubMed Central: PMC3539517].

26. Luo H, Lv XD, Wang GE, Li YF, Kurihara H, He RR. Anti-inflammatory effects of anthocyanins-rich extract from bilberry (Vaccinium myrtillus L.) on croton oil-induced ear edema and Propionibacterium acnes plus LPS-induced liver damage in mice. Int J Food Sci Nutr. 2014;65(5):594-601. doi: 10.3109/09637486.2014.886184. [PubMed: 24548119].

27. Wang Y, Zhao L, Lu F, Yang X, Deng Q, Ji B, et al. Retinoprotective effects of bilberry anthocyanins via antioxidant, anti-inflammatory, and anti-apoptotic mechanisms in a visible light-induced retinal degeneration model in pigmented rabbits. Molecules. 2015;20(12):22395-410. doi: 10.3390/molecules201219785. [PubMed: 26694327].

28. Baum M, Schantz M, Leick S, Berg S, Betz M, Frank K, et al. Is the antioxidative effectiveness of a bilberry extract influenced by encapsulation? J Sci Food Agric. 2014;94(11):2301-7. doi: 10.1002/jsfa.6558. [PubMed: 24395460].

29. Sharp PE, La regina MC. Anatomical and physiological features. In: Sharp PE, Villano JS, editors. The laboratory rat. 2nd ed. Baco Raton, Florida: CRC Press Taylor\& Francis; 2012. p. 7-21.

30. Kim J, Choe MA. [Effects of antioxidant on reduction of hindlimb muscle atrophy induced by cisplatin in rats]. J Korean Acad Nurs. 2014;44(4):371-80. Korean. doi: 10.4040/jkan.2014.44.4.371. [PubMed: 25231802].

31. Hojman P, Fjelbye J, Zerahn B, Christensen JF, Dethlefsen C, Lonkvist $\mathrm{CK}$, et al. Voluntary exercise prevents cisplatin-induced muscle wasting during chemotherapy in mice. PLoS One. 2014;9(9). e109030. doi: 10.1371/journal.pone.0109030. [PubMed: 25268807]. [PubMed Central: PMC4182656].

32. Sakai H, Sagara A, Arakawa K, Sugiyama R, Hirosaki A, Takase K, et al.
Mechanisms of cisplatin-induced muscle atrophy. Toxicol Appl Pharmacol. 2014;278(2):190-9. doi: 10.1016/j.taap.2014.05.001. [PubMed: 24823295].

33. Bassel-Duby R, Olson EN. Signaling pathways in skeletal muscle remodeling. Annu Rev Biochem. 2006;75:19-37. doi: 10.1146/annurev.biochem.75.103004.142622. [PubMed:16756483].

34. Seeram NP. Berry fruits: Compositional elements, biochemical activities, and the impact of their intake on human health, performance, and disease. J Agric Food Chem. 2008;56(3):627-9. doi: 10.1021/jf071988k. [PubMed: 18211023].

35. Afzal M, Safer AM, Menon M. Green tea polyphenols and their potential role in health and disease. Inflammopharmacology. 2015;23(4):15161. doi: 10.1007/s10787-015-0236-1. [PubMed: 26164000].

36. Kalt W, Forney CF, Martin A, Prior RL. Antioxidant capacity, vitamin C, phenolics, and anthocyanins after fresh storage of small fruits. J Agric Food Chem. 1999;47(11):4638-44. [PubMed: 10552863].

37. Chu W, Cheung SCM, Lau RAW, Benzie IFF. Bilberry (Vaccinium myrtillus L.). In: Benzie IFF, Wachtel-Galor S, editors. Herbal medicine: Biomolecular and clinical aspects. 2nd ed. Baco Raton, Florida: CRC Press Taylor \& Francis; 2011.

38. Giorgi C, Romagnoli A, Pinton P, Rizzuto R. Ca2+ signaling, mitochondria and cell death. Curr Mol Med. 2008;8(2):119-30. [PubMed: 18336292].

39. Pinton P, Giorgi C, Siviero R, Zecchini E, Rizzuto R. Calcium and apoptosis: ER-mitochondria Ca2+ transfer in the control of apoptosis. Oncogene. 2008;27(50):6407-18. doi: 10.1038/onc.2008.308. [PubMed: 18955969]. [PubMed Central: PMC2844952].

40. Bhat M, Kalam R, Qadri SS, Madabushi S, Ismail A. Vitamin D deficiency-induced muscle wasting occurs through the ubiquitin proteasome pathway and is partially corrected by calcium in male rats. Endocrinology. 2013;154(11):4018-29. doi: 10.1210/en.2013-1369. [PubMed: 23928374].

41. Wagatsuma A, Fujimoto K, Yamada S. Effect of treatment with nifedipine, an L-type calcium channel blocker, on muscular atrophy induced by hindlimb immobilization. Scand J Med Sci Sports. 2002;12(1):26-30. [PubMed: 11985762]. 